Dossiê: Judaísmo: religião, cultura, nação - Artigo Original (c) $\underset{\mathrm{EY}}{\mathrm{B}}$

\title{
0 gênero apocalíptico na literatura judaica intertestamentária: reflexões à luz da teoria literária em diálogo com a teologia
}

\author{
The apocalyptic genre in the intertestamentary Jewish literature: reflections \\ in the light of literary theory in dialogue with theology
}

Cristiano Camilo Lopes *

\begin{abstract}
Resumo
Neste artigo, propõe-se discutir a formação, composição e características do gênero apocalíptico. Para isso, são feitas considerações sobre o conceito de gênero literário à luz da Teoria Literária (COELHO, WELLEK; WARREN, MARCUSCHI, ZILBERMAN) e dos estudos da Teologia e da Hermenêutica (COLLINS, COSTA, KOSTENBERGER; FEE; STUART, PATTERSON, OSBORNE, ROWLEY, RYKEN). A princípio, levou-se em consideração as propostas da Teoria Literária e de teólogos bíblicos serviram de referencial teórico para o desenvolvimento das discussões conceituais do gênero. Em seguida, avaliou-se o contexto histórico do Período Interbíblico (aspectos sociais, culturais e religiosos), com vista a observar sua relação com a configuração interna do gênero apocalíptico (texto-contexto, forma, conteúdo, função). E, por fim, verificou-se que o gênero apocalíptico apresenta características específicas que o singularizam e que puderam ser descritas com base nas discussões propostas nesta pesquisa. Dentre esses elementos destacam-se: um meio de comunicação visionário ou revelatório; linguagem simbólica, figurada e metafórica; dualismo entre as realidades terrena e celestial.
\end{abstract}

Palavras-chave: literatura apocalíptica; período interbíblico; gêneros literários.

\begin{abstract}
In this article, it is proposed to discuss a formation, composition and characteristics of the apocalyptic genre. Therefore, it mades for the concept of literary genres in the light of Literary Theory (COELHO, WELLEK; WARREN, MARCUSCHI, ZILBERMAN) and studies of Theology and Hermeneutics (COLLINS, COSTA, KOSTENBERGER; FEE; STUART, PATTERSON, OSBORNE, ROWLEY, RYKEN). At first, considered the contribution of Literary Theory and biblical theologians served as a theoretical reference for the development of conceptual discussions of the genre. Next, we evaluate the historical context of the Interbiblical Period (social, cultural and religious aspects), in order to observe its relation with an internal configuration of the apocalyptic genre (textcontext / form / content / function). And, finally, it was verified that the apocalyptic genres presents specific characteristics that singularize it and that could be described based on the discussions proposed in the research. Among these elements stand out: a means of visionary or revelatory communication; symbolic, figurative and metaphorical language; dualism between earthly and heavenly realities.
\end{abstract}

Keywords: apocalyptic literature; interbiblical period; literary genres.

Artigo submetido em 21 de março de 2018 e aprovado em 28 de abril de 2019.

* Doutor em Letras pela FFLCH-USP. Professor de Teologia na Universidade Presbiteriana Mackenzie. País de origem: Brasil. E-mail: cristianoclopes@hotmail.com 


\section{Introdução}

Neste artigo, propõe-se discutir o tema gênero apocalíptico refletindo a respeito de sua constituição e suas características, bem como seu desenvolvimento na literatura judaica intertestamentária.

O desenvolvimento desta temática justifica-se por vários motivos, a começar pelo fato de que o gênero apocalíptico nos apresenta um tipo de escrita bastante peculiar que não é característico dos nossos dias, o que nos leva a avaliar historicamente as circunstâncias que viabilizaram a produção desse tipo de literatura que se pode identificar no final do Novo Testamento, no livro intitulado Apocalipse.

Toda a discussão a respeito dos gêneros literários deve servir ao teólogo como ferramenta para sua lida com a mensagem do texto bíblico. Os estudos literários servem (também) para mostrar que cada texto carrega uma mensagem e os aspectos formais do gênero nos ajudam a expor o conteúdo do texto. Trata-se, então, da relação entre forma e conteúdo: todo texto é um combinado harmônico entre um conteúdo expresso em uma forma.

Além disso, vale lembrar o que Ryken (2017, p. 9) acertadamente afirmou: "nenhum estudo especializado da Bíblia em qualquer disciplina está limitado à terminologia em uso nos tempos bíblicos. Um estudante contemporâneo de gramática, de língua hebraica e da grega usa termos que os escritores da Bíblia não usavam.” Portanto, o uso da terminologia pertencente a Teoria Literária, ajuda-nos a ver a utilidade dessa nomenclatura para os estudos da Hermenêutica bíblica. Vale ressaltar que o uso dessa terminologia e sua lógica não acrescenta nada à mensagem do texto bíblico, o que nos dá liberdade de trabalho técnico com as formas para, então, chegar-se ao conteúdo.

O estudo dos gêneros literários e de sua composição pode auxiliar os estudos da hermenêutica bíblica, haja vista que, como diz Osborne (2009, p. 227-228), “o gênero funciona como uma valiosa conexão entre o texto e o leitor” e é preciso 
“perceber as características dos gêneros antigos como uma chave para interpretar os textos bíblicos”.

Além disso, os gêneros funcionam como instituições no campo da literatura e, assim, estabelecem suas próprias regras. Quando se estuda uma obra literária, "podemos trabalhar, nos expressar por meio das instituições existentes, criar novas ou seguir em frente [...]" (WELLEK; WARREN, 2003, p. 307). Esses são os principais passos que um autor segue em seu processo criativo. Daí a importância de investigar-se o surgimento de um gênero literário.

Os gêneros permitem-nos classificar a literatura por meio de aspectos internos (estrutura/organização), e também externos (tempo/espaço), ou seja, descrever as características de um gênero permite-nos o agrupamento de determinadas obras em uma determinada categoria bem como o delineamento de marcas internas e (possíveis) influências externas fundamentais desses gêneros. Vale destacar também que os gêneros mudam à medida que novas obras surgem. Por isso, investigar a história é importante, pois, ao observá-la, é possível avaliar as propriedades e objetivos estéticos dos gêneros em cada momento.

Sabe-se que o gênero apocalíptico configurou-se no período intertestamentário na literatura judaica e serviu de modelo para muitos escritos posteriores a esse período, inclusive para o Apocalipse. Por isso, investigar sua história e características principais é fundamental para identificar os acréscimos e mudanças ocorridas com o passar do tempo e nos diferentes espaços. Nesse sentido, Osborne (2009, p. 351) chama-nos a atenção para o fato de que "esse material compreende um período que se estende do século VII A.C. ao século II d.C. A literatura extracanônica é essencial para se obter uma perspectiva e um controle adequados no estudo do material canônico.

O objetivo geral deste estudo, portanto, é investigar o desenvolvimento do gênero apocalíptico na literatura judaica intertestamentária e sua possível relação com a Teoria Literária, avaliando, sobretudo, as características do gênero apocalíptico. Para isso, assentam-se os seguintes objetivos específicos: expor a 
noção de gênero literário de acordo com a Teoria Literária; discorrer sobre os aspectos do Período Interbíblico que proporcionaram o desenvolvimento do gênero e sua configuração literária com características próprias; apresentar as principais características gerais, forma, conteúdo e função do gênero apocalíptico.

Com relação ao referencial teórico para a discussão de gênero, esta pesquisa se pautará nos conceitos de gênero literário à luz da Arte Poética, de Aristóteles em diálogo com a ideia de tipos textuais de Marcuschi (2008) no campo do estudo dos gêneros textuais. Além disso, apresentaremos as contribuições na área de Teoria Literária Moderna com o intuito de avaliar como as ideias contemporâneas têm discutido o gênero literário. Aqui utilizamos as contribuições de Coelho (1976) e Wellek e Warren (2003).

Em relação à discussão de gênero apocalíptico, selecionaram-se obras que versam sobre a história da literatura apocalíptica, tanto do Antigo como do Novo Testamento: Collins (1979; 1998; 2000), Rowley (1980), Soares (2008), e obras da Hermenêutica Bíblica que apresentam as principais características do gênero apocalíptico, a saber: Osborne (2009), Fee; Stuart (2011) e Köstenberger; Patt (2015). Somam-se a isso as discussões da própria Teologia com os autores Dana (1980), ENCICLOPÉDIA DA BÍBLIA (2008), Costa (1992).

Com o intuito de cumprir as ações propostas nos objetivos, esta pesquisa foi realizada por meio de pesquisa bibliográfica, pautada em material já publicado que versa sobre gênero literário, literatura apocalíptica, período interbíblico e interpretação de gênero apocalíptico. Para o trabalho com as fontes de informação, foram selecionadas obras de referência na área da Teoria Literária (considerações sobre os gêneros literários), da Hermenêutica Bíblica (características do gênero apocalíptico) e da própria Teologia (história do Período Interbíblico). Após a leitura desses textos, procedeu-se ao cotejo de cada uma das obras para, então, prosseguirse com a confecção das seções. 


\section{0 gênero literário à luz da teoria literária}

Estudar os gêneros literários também é uma maneira de se conhecer um povo. Uma vez que a literatura é arte e expressão, e utiliza os aspectos verbo-vocovisuais, entendemos que as várias formas dessas expressões têm muito a nos ensinar, pois "toda cultura tem os seus gêneros: a chinesa, a árabe, a irlandesa [...]" (WELLEK; WARREN, 2003, p. 319). Por isso, o estudo dos gêneros mostra-nos o desenvolvimento literário de um povo, um lugar ou uma época.

Marcuschi (2008, p. 154) chama a atenção para o fato de que não há como ocorrer a produção textual em um determinado povo sem que isso se estruture por meio de gêneros textuais. Em suas palavras: “[...] toda a manifestação verbal se dá sempre por meio de textos realizados em algum gênero. Em outros termos, a comunicação verbal só é possível por algum gênero textual”.

Então, é válido destacar que a discussão a respeito da importância dos gêneros literários não é uma percepção moderna, pois, na Antiguidade, já se falava a respeito dos gêneros. Naquela época os gêneros sempre estiveram ligados estritamente à literatura. Já hoje se percebe um entrecruzamento de áreas do conhecimento na questão dos gêneros textuais, configurando um aspecto multidisciplinar.

A expressão 'gênero' esteve, na tradição ocidental, especialmente ligada aos gêneros literários, cuja análise se inicia com Platão para se firmar com Aristóteles, passando por Horácio e Quintiliano, pela Idade Média, o Renascimento e a Modernidade, até os primórdios do século XX. Atualmente, a noção de gênero já não mais se vincula apenas à literatura, como lembra Swales (1990, p. 33), ao dizer que 'hoje, gênero é facilmente usado para referir uma categoria distintiva de discurso de qualquer tipo, falado ou escrito, com ou sem aspirações literárias””. (MARCUSCHI, 2008, p. 147).

Para Wellek e Warren (2003, p. 318), aquele que trabalha com os gêneros literários deve estar atento ao fato de que a dicotomia clássico/moderno às vezes pode ser perigosa no que concerne ao gênero: 
Qualquer um interessado na teoria dos gêneros deve ter cuidado para não confundir as diferenças distintivas entre a teoria "clássica" e a moderna. A teoria clássica é regulamentadora e prescritiva, embora as suas "regras" não sejam o autoritarismo tolo ainda atribuído frequentemente a elas. A teoria clássica não crê que um gênero difere de outro, na natureza e na glória, mas também que devem ser mantidos separados, que não devemos permitir que se misturem. (WELLEK; WARREN, 2003, p. 318).

Nos estudos clássicos, temos as diretrizes fundamentais da teoria dos gêneros literários. E, mesmo na contemporaneidade, entendemos que suas regras não estão em desuso, muito pelo contrário, quanto mais se entende os traços fundamentais dos gêneros (propostos pelos autores clássicos), mais se compreende suas variações, derivações, alterações (acréscimos e decréscimos). Assim, o moderno (e também o contemporâneo) deve buscar as referências nos clássicos uma vez que "a moderna teoria dos gêneros é descritiva, não se limita o número de tipos possíveis e não prescreve regras a autores. Supõe que os tipos tradicionais podem ser 'misturados' e produzir um novo tipo [...]" (WELEK; WARREN, 2003, p. $320)$.

É importante destacar que os autores clássicos entendiam o gênero como algo de expressão social e cultural. Como veremos adiante, os gêneros foram acompanhando a história das regiões e dos povos onde se desenvolveram. Essa é mais uma razão para se pensar a respeito dos gêneros a partir dos clássicos: "a teoria clássica também teve a sua diferenciação social de gêneros. A epopeia e a tragédia lidam com os assuntos de reis e nobres, a comédia com os da classe média (a cidade, a burguesia), e a sátira e a farsa com as pessoas comuns." (WELEK; WARREN, 2003, p. 319).

Os estudos clássicos também apontam o fato de que uma literatura gera outra literatura, isto é, um autor, em seu processo criativo, utiliza o material já conhecido e também já provado pelo leitor, para compor sua obra: "o gênero representa [...] uma soma de recursos estéticos possíveis, disponíveis para o escritor e já inteligíveis para o leitor. O bom escritor, em parte, conforma-se ao gênero tal como existe e, em parte, alarga-o." (WELEK; WARREN, 2003, p. 320). Diante disso, cumpre-nos discutir a teoria dos gêneros no pensamento de Aristóteles. 


\subsection{Os processos formativos de um gênero}

Iniciamos com a seguinte pergunta: Por que os escritores canônicos ou extracanônicos tiveram alguns elementos básicos na composição de literatura apocalíptica? A resposta é que cada gênero textual tem propósito determinado definido, e isso garante a sua recorrência nas criações de vários autores. Em outras palavras, os autores veem no objetivo do gênero uma forma que dá conta daquilo que desejam expressar em sua criação artística.

Assim, "todos os gêneros têm uma forma e uma função, bem como um estilo e um conteúdo, mas sua determinação ocorre basicamente pela função, e não pela forma (MARCUSCHI, 2008, p. 150). Contudo, percebemos também que os autores das literaturas apocalípticas conhecem bem as fronteiras do gênero e desenvolvem esses limites. É o caso, por exemplo, do Apocalipse (canônico) escrito pelo apóstolo João: muitos autores o definem como uma epístola apocalíptico-profética, tendo em vista o trânsito pelas fronteiras bem delimitadas desses três gêneros presentes nas Escrituras.

Em decorrência disso, refletindo sobre as características de um gênero, pode-se perguntar: por que os gêneros mudam? Porque o gênero é dinâmico e, portanto, sofre mudanças ao longo dos tempos. Entretanto, há uma identidade expressa por meio de alguns elementos fundamentais, por isso as considerações sobre um determinado gênero serão bem feitas: "desde que não concebamos os gêneros como modelos estanques, nem como estruturas rígidas, mas como formas culturais e cognitivas de ação social corporificadas de modo particular na linguagem, temos de ver os gêneros como entidades dinâmicas" (MARCUSCHI, 2008, p. 156). Diante disso, iniciamos nossa reflexão a respeito do processo criativo de um gênero literário com a seguinte pergunta: o que vem a ser um gênero literário?

Nosso ponto de partida na resposta é entender que o gênero literário é uma espécie de texto diferenciado de outros tipos por meio de sua estrutura: "Há uma 
série de elementos estruturais que na obra concorrem para a determinação do seu gênero" (COELHO, 1976, p. 40). E, em seguida, acrescentamos: como nasce um gênero literário? Mais especificamente: de que maneira o escritor equilibra os aspectos do seu mundo interior com o mundo à sua volta?

Para responder a essas perguntas, levamos em consideração que o autor (sendo poeta - criador/imitador) é também um observador. O poeta, ao imitar, observa os estilos dos homens focando, então, nos diversos tipos de caráteres apreendidos por sua observação: “a observação de diversos tipos humanos, de acordo com a variedade de caráteres existentes (normais, virtuosos, viciosos) fornece ao imitador o cimento para a construção de sua arte” (BITTAR, 2003, p. 1385). Dessa forma, por meio das atitudes de observação do autor em seu processo criativo, torna-se possível tecer algumas considerações a respeito da formação de um gênero literário. Para essas considerações, recorremos às ideias de Coelho (1976).

Como vimos acima, para compor sua arte, o autor capta o mundo exterior ao olhar para determinados objetos expressos nos diversos tipos humanos, juntamente com as circunstâncias que os envolvem. Por isso, o primeiro aspecto do processo criativo de um gênero diz respeito ao autor e sua captação exterior por meio da observação. O segundo aspecto volta-se para a subjetividade, isto é, ele busca dentro de si as ideias quando evoca suas emoções e percepções. Em seguida, temos o lócus enunciativo do autor, ou seja, seu lugar de fala a partir do qual ele julga, interpreta e analisa o contexto em que está inserido, ou do qual ele retrata em sua obra. E o último aspecto diz respeito ao fato de o autor transformar suas ideias em linguagem valendo-se de recursos como figuras de linguagem, funções da linguagem e tipos textuais (com alterações ou expansões). Tudo isso de acordo com o seu objetivo de comunicação.

De outra maneira, Ryken (2017, p. 118-119) explica o processo criativo por meio de alguns aspectos do texto literário. Esses aspectos remetem não só ao texto literário, mas também à formação de um determinado gênero. Inicialmente, Ryken 
(2017, p. 118-119) ressalta que a literatura é registro em linguagem das muitas experiências humanas sejam na vida concreta, ou na maneira de se ver ou interpretar o mundo. Para isso, o artista "cria um universo autônomo, onde os seres, as coisas, os fatos, o tempo e o espaço, assemelham-se aos que podemos reconhecer no mundo real que nos cerca.” (COELHO, 1976, p. 23) Ocorre, então, uma transformação de realidade, proporcionada pela literatura, em que o leitor é inserido no universo ficcional. Além disso, a literatura serve de suporte exterior para que o homem tenha acesso ao mundo, haja vista que, para se expressar, ela se vale de um instrumento essencial na comunicação entre os homens: a linguagem.

De acordo com Regina Zilberman, a literatura trabalha com dois elementos adequados para vivência, experiência e compreensão do real:

uma história, que apresenta, de maneira sistemática, as relações presentes na realidade, que a criança não pode perceber por conta própria [...] - a linguagem, que é o mediador entre a criança e o mundo. De modo que, propiciando, pela leitura, um alargamento do domínio linguístico, a literatura preencherá uma função de conhecimento. (ZILBERMAN, 2003, p. 45, grifo nosso).

Por meio desses elementos estruturais, o leitor prova a realidade de forma experiencial e, com a linguagem adquirida, pode exercitar sua decodificação do conhecimento apreendido: “[...] transforma-se num meio de acesso ao real, na medida em que facilita a ordenação de experiências existenciais, pelo conhecimento de histórias, e a expansão de seu domínio linguístico.” (ZILBERMAN, 2003, p. 46).

Um outro aspecto apontado por Ryken (2017, p. 118-119) diz respeito à natureza literária dos gêneros. A partir do momento em que um texto é exprime os anseios do autor por meio de uma linguagem carregada de sentido, e isso revele o trabalho artístico do autor que se apresenta como um artista das palavras, tem-se aí um texto com natureza literária. Isso faz com que o texto literário se apresente de forma diferente de um texto descritivo ou expositivo, por exemplo: 
Um sermão pode ser somente expositivo, mas se o escritor o adorna com técnicas literárias, ele torna-se literário. O Sermão da Montanha pregado por Jesus é tão cheio de técnica literária que é uma verdadeira referência como elaboração artística [...] a literatura chama a atenção para si mesma, sendo distinta do discurso expositivo diário. Este, no melhor dos casos, é transparente e não chama atenção para si mesmo. A literatura nos incita a prestar atenção ao "modo" de ser do discurso. (RYKEN, 2017, p. 119).

Como nosso objeto de estudo neste artigo é a literatura apocalíptica, é possível estabelecer um paralelo entre os termos que geralmente são empregados para definir esse tipo de literatura e as atitudes criativas do autor. Nos estudos da Hermenêutica Bíblica, é comum encontrar os termos ${ }^{1}$ apocalíptico, apocalipsismo e apocalipse como referência ao gênero apocalíptico.

Por isso, as considerações a respeito do processo criativo do gênero por meio de um autor podem servir de guia para o uso dos termos que envolvem o gênero apocalíptico. Ao aplicarmos as ideias da teoria literária para a nomenclatura da Teologia, podemos considerar que: o termo apocalíptico diz respeito à cosmovisão do tipo de literatura, ou seja, literatura que trata das questões do fim, ou dos tempos de dificuldade; o termo apocalipsismo aponta para a ideologia ou teologia do autor; são as motivações do autor que acabam por mostrá-lo como um homem de seu tempo e espaço (o lócus enunciativo); o termo apocalipse se refere aos aspectos específicos da linguagem literária que caracterizam o gênero, e isso remete a um estilo recorrente entre os judeus especialmente na literatura judaica produzida aproximadamente entre 400 a.C. e 300 d.C.

Feitas essas considerações, passaremos a discutir de que maneira os elementos contextuais do período interbíblico contribuíram para a intensificação do gênero apocalíptico na literatura judaica.

\footnotetext{
${ }^{1}$ Verbetes do Dicionário teológico do Novo Testamento (REID, 2012). Os termos são apresentados nesta seção, porém serão desenvolvidos no próximo capítulo.
} 


\section{Aspectos históricos do gênero apocalíptico}

A literatura apocalíptica judaica é caracterizada por os aspectos formais da literatura, bem como pela cosmovisão inerente ao texto literário. De acordo com Osborne (2014, p. 16) esse gênero literário se intensificou entre 200 a.C. e 100 d.C., porém no AT já haviam manifestações desse tipo de literatura: “[...] há também alguns protótipos bíblico como Isaías 24-27, Ezequiel 37-39, Zacarias e principalmente Daniel" O autor ainda destaca que as principais características desse gênero estão presentes no Apocalipse de João. Nosso objetivo, então, é tecer uma rede reflexiva a respeito dos estudos dessa literatura para, assim, discorrer a respeito dos elementos que impulsionaram sua produção.

Os anos 1940-1970 marcaram um reavivamento nos estudos do gênero apocalíptico dando início, então, a um primeiro período desse reavivamento. Obras como The rediscovery of apocalyptic (KOCH, 1970), The dawn of apocalyptic (HANSON, 1979) e A importância da literatura apocalíptica (ROWLEY, 1980) serviram de base para os estudos contemporâneos do gênero em questão.

A partir dessas pesquisas, nos anos 1990, surgiram novas reflexões que apresentaram um caráter mais específico na área bíblico-teológica, e, assim, o objetivo de pesquisadores como J. J. Collins foi definir o que vem a ser um apocalipse. Essa definição gerou os conceitos que usualmente se aplicam ao gênero utilizado pelos estudiosos na área da Teologia.

A partir dos estudos do século XX de Koch e Collins, entendeu-se que o termo apocalipse foi usado a partir do Apocalipse de João (mais especificamente o versículo 1 do capítulo 1) para referir-se a obras que tratem de questões relacionadas ao fim do mundo e ao mundo vindouro. No entanto, com os estudos literários aplicados a esse tipo de gênero encontrado nos livros sagrados, passou-se a usar o termo apocalipse para o tipo de literatura produzida pelos judeus na região da Palestina no período de IV a.C. a II d.C.: 
Um segundo e mais desenvolvido movimento apocalíptico ocorreu no século II a.C. No período pós-macabeu, o movimento foi associado com o Hassidim [...] tratava-se mais de um modo de pensar, um modo de olhar a vida. Era, em primeiro lugar, um meio divinamente escolhido de revelação e, então, se tornou uma visão de mundo que atravessou diferentes seitas judaicas. Sua manifestação se deu em todas elas e em diferentes tempos (com exceção dos saduceus). O mais importante é que esse movimento proporcionou uma das ligações mais claras entre o judaísmo e o cristianismo, muito mais direta do que qualquer partido em particular. (OSBORNE, 2009, p. 370).

Para a elaboração de uma pesquisa a respeito do gênero apocalíptico, faz-se necessário tecer considerações sobre o Período Interbíblico, pois é nele que a literatura judaica floresce. Nesse período:

os judeus tiveram uma fecunda e brilhante literatura que narra de forma dramática e corajosa este período. Nas obras desta época encontramos registrados os seus sofrimentos e esperanças; ouvimos o grito do povo que clama pelo socorro divino sempre acompanhado da esperança que é o apanágio dos vivos. (COSTA, 1992, p. 16).

Como nosso foco, neste momento, é discutir o gênero literário, apoiamo-nos na ideia de que, no termo apocalipse (aplicado ao tipo de literatura produzida no período de IV a.C. a III d.C.), subjazem os termos apocalíptico e apocalipsismo.

O termo apocalíptico remete à cosmovisão que imperava nos autores dos textos que falavam do fim do mundo. Se levarmos em conta que os judeus do período interbíblico estavam sem a voz divina desde o profeta canônico Malaquias, fica claro que esse tipo de cosmovisão serviu de lente interpretativa do mundo mais adequada para eles, pois ela traz em seu bojo a esperança de um mundo vindouro. Nessa esperança de um reino vindouro e uma vez desprovidos da voz divina, os judeus procuraram dilatar a voz de Deus que se fez ouvir nas profecias do AT canônico, uma vez que tinham nesses textos a referência para conhecimento de Deus.

Em decorrência dessa esperança, os textos desse período refletem a ideia de um julgamento final para aqueles que perseguiram o povo de Deus e não se renderam ao Deus de Israel. E, diferentemente da profecia que era dada por Deus aos profetas, essas perspectivas cósmicas eram agora dadas por Deus (na ótica dos 
textos em questão) como forma de consolo e esperança para o seu povo. Não há, portanto, uma intervenção divina direta no contexto, pelo contrário, o que se tem é uma promessa de que haverá um julgamento e um mundo celestial diferente.

Já o termo apocalipsismo evoca as questões sociais dos autores dos textos em questão, "é um termo usado em referência ao tipo específico de expectativa escatológica característico dos primeiros apocalipses judeus e cristãos.” (DICIONÁRIO TEOLÓGICO DO NOVO TESTAMENTO, 2012, p. 102) Nesse sentido, ao discorrer sobre essas questões, devemos levar em consideração os aspectos religiosos e sociais que contribuíram para a produção desse tipo de literatura no Período Interbíblico.

\subsection{Fatores que contribuíram para a produção da literatura judaica}

Os livros de Esdras, Neemias, Ageu, Zacarias e Malaquias mostram o período do regresso dos judeus à sua terra. Durante 70 anos, eles passaram presos na Babilônia até que, em 539 - c. 515 a.C., Ciro (governante de Pérsia) baixou um decreto (édito de Ciro da Pérsia) permitindo que os exilados voltassem para Jerusalém.

Se observarmos a história do povo de Deus no Antigo Testamento, veremos que o culto a outros deuses foi um elemento central na desobediência dos judeus aos princípios que Deus estabeleceu, quando entrou em aliança com Seu povo (Dt 29.9,12,14,21). Para alertar seu povo, Deus enviou profetas chamando os judeus de volta à aliança por meio da observância aos princípios da lei no coração. Referências bíblicas do AT como Isaias 54.9, 10; Jeremias 31.3-6 evidenciam que Deus trouxe o exílio como expressão de julgamento para os judeus. Assim, a história do AT mostra-nos que o povo não obedeceu a Deus e, então, vieram os cativeiros como expressão do juízo divino.

No regresso para sua terra, narrado nos livros de Esdras e Neemias, fica claro que o povo de Deus voltou com uma lição apreendida: dedicação à lei do Senhor e o consequente culto ao único Deus. Por meio da leitura dos livros I 
Macabeus, principalmente, podemos ver como a Lei de Moisés com seus ritos, mandamentos e princípios assumiram um alvo para a vida dali para a frente.

Um dos maiores benefícios do cativeiro babilônico, foi o de colocar um marco entre o povo de Deus, para mostrar-nos o velho e o novo judeu. Isto é, o judeu velho, pessimista, vencido sem esperanças nas promessas do Eterno e o judeu novo, despertado, transformado, curado de sua idolatria e pronto a obedecer fielmente à Voz de Deus. Os dois tipos de judeus voltaram a Jerusalém, mas o novo venceu o velho, de sorte que todas as tendências idolátricas e derrotistas foram suplantadas pela atitude otimista dos judeus transformados [...]. (TOGNINI, 1987, p. 17).

A experiência do cativeiro serviu para curar, ao menos externamente, a idolatria dos judeus, mas, no lugar disso, o coração desse povo passou a ser regido pela observância ao legalismo judaico. Então, para eles, o futuro Messias deveria apresentar uma aura maior do que a de Moisés, o escritor dessa lei.

Ademais, o exílio serviu para fortalecer a convicção de que o Messias viria. Por meio de uma compreensão mais profunda das Escrituras, os judeus passaram a aguardar a manifestação soberana de Deus ao enviar o Messias para salvá-los. A convicção de que o Senhor é o único Deus passou a reger a conduta do povo que regressou do exílio suportando (e resistindo) até mesmo a dominação da cultura grega durante o período interbíblico:

No período interbíblico o judaísmo apresentou um quadro complexo no que se refere à vida religiosa; isto porque surgiram diversas seitas e partidos, os quais apresentaram costumes, crenças e objetivos diferentes. Todavia, estes grupos religiosos, apesar das suas divergências éticas e teológicas, sustentavam uma ideia em comum, a saber: a ideia augusta do Deus que viria reinar como soberano, o Deus vivo, presente e poderoso. (COSTA, 1992, p. 26).

Com o regresso para Jerusalém, após o cativeiro, os judeus foram cada vez mais se conscientizando da superioridade da autoridade escrita em relação a oral. De acordo com Neemias 8-10 vemos que o povo se consagra ao livro que Deus concedeu a eles: "é impressionante ver o papel que documentos escritos desempenham no livro [...] o documento escrito mais importante não é de origem humana, mas é a Torá de Yahweh.” (PROVAN; LONG; LONGMAN, 2016, p. 466). 
Esse apego ao texto (oral e escrito) da lei foi um fator determinante para a produção literária do período interbíblico. Os judeus começaram a produzir literatura de várias ordens a partir desse fervor legalista²:

Dessa nostalgia nasceram muitos livros apócrifos [...] achamo-la no espírito estreito e nacionalista dos judeus em interpretar a profecia [...] recorriam às profecias do Velho Testamento e tudo faziam para que estas atendessem às exigências de Israel. (TOGNINI, 1987, p. 23).

Assim sendo, a produção literária desse período foi intensificada pelo fervor legalista, suscitando uma firme convicção de que o Messias seria enviado por Deus para salvá-los. Costa (1992) descreve de que maneira o fervor pela lei gerou a produção literária dos judeus no Período Interbíblico.

Para que pudesse acontecer essa autoconsciência, fazia-se necessário enfatizar o estudo da lei, e concomitantemente mostrar a relevância e a singularidade do culto judeu prestado a Deus. Por isso, este grupo, visando atingir ao seu objetivo, escreveu obras nas quais a lei era enfatizada e reverenciada; os ritos levíticos foram pintados com cores vivas, focalizando sempre o seu valor para a vida e preservação do povo. (COSTA, 1992).

Por meio de sua argumentação, percebe-se que os judeus se valeram da imaginação criadora (enquanto forma) e do uso da lei (no conteúdo) desenvolvendo, assim, as características internas do gênero apocalíptico: "há um amplo consenso de que os apocalipses judaicos foram escritos ou revisados em períodos de crise social ou política, embora essas crises pudessem estar inseridas numa ampla escala que ia do real ao imaginário.” (DICIONÁRIO TEOLÓGICO DO NOVO TESTAMENTO, 2012, p. 102).

Há pelo menos duas linhas que tentam explicar os fundamentos do imaginário criador dos escritores dos apocalipses judaicos desse período: a relação entre os apocalipses judaicos e as profecias do AT, e a relação entre apocalipses judaicos e a literatura sapiencial do AT.

\footnotetext{
${ }^{2} \mathrm{O}$ termo é utilizado aqui como referência ao apego que os judeus tinham aos preceitos legais do AT.
} 
Com relação ao primeiro aspecto citado, há o fato de que há semelhanças nos apocalipses judaicos com textos proféticos pós-exílicos como: Zacarias 1-6, 914; Isaias 24, 27, 56; Joel. Esses textos reverberam na fase inicial da produção da literatura judaica. Entretanto, cumpre-nos destacar também que há descontinuidade entre os textos proféticos e os apocalipses judaicos. Hanson (1979) descreve que a profecia do AT sofreu muitas variações até chegar o início da literatura judaica.

O que se tem como certo na relação apocalipse judaico e profecia do AT é a escatologia embora exista uma diferença entre a escatologia dos profetas do AT e a do Período Interbíblico: "a escatologia profética era uma perspectiva otimista que antevia Deus restaurando no fim de todas as coisas as circunstâncias prístinas e originariamente idílicas [...]”. Já a escatologia apocalíptica é tida como pessimista, pois não vê que o presente conduz ao futuro, pelo contrário ela "vê o futuro interrompendo o presente" (DICIONÁRIO TEOLÓGICO DO NOVO TESTAMENTO, 2012, p. 103) Assim, vemos que a salvação escatológica vem por meio dos acontecimentos deste mundo e não pelo irrompimento de um mundo vindouro.

Em outra vertente diferente a que vimos acima, há autores como Gerhard Von $\operatorname{Rad}(1965)$ que rejeitam a ideia de que a origem da literatura apocalíptica esteja nas profecias do AT. De acordo com essa perspectiva os temas presentes na literatura sapiencial e nos apocalipses judaicos constitui um argumento que sustenta uma relação de fonte e influência entre essas literaturas. Os temas que ligam as duas literaturas são:

1) tanto os sábios e experientes quanto os apocaliptistas são chamados "sábios", e ambos preservam seus ensinos na forma escrita, muitas vezes realçando seu "conhecimento" especial e a antiguidade desse conhecimento; 2) ambos mostram tendências individualistas e universalistas; 3 ) ambos se preocupam com os mistérios da natureza pela perspectiva celestial; 4) ambos refletem uma visão determinista da história. (DICIONÁRIO TEOLÓGICO DO NOVO TESTAMENTO, 2012, p. 103). 
Diante disso, percebemos que a questão das origens dos apocalipses judaicos ainda permanece aberta: de um lado há uma vertente que vê a origem nas profecias do AT, por aspectos internos da história dos judeus como o exílio e a lida com as outras nações no Período Interbíblico. Por outro lado, há uma linha que é mais generalista que atribui o processo criativo dos apocalipses judaicos a um intercâmbio literário com o mundo grego, ou seja, "uma fusão das ideias religiosas do Ocidente com as do Oriente.” (DICIONÁRIO TEOLÓGICO DO NOVO TESTAMENTO, 2012, p. 102).

\subsection{Jerusalém e Alexandria}

O conquistador grego Alexandre tirou a cidade de Jerusalém das mãos dos persas em 322 a.C. Essa data marcou o início do período grego em Jerusalém. No período de Alexandre, a maior parte dos gregos parecem ter tratado os judeus com respeito por suas questões religiosas. Com a sua morte em 323 a.C., o império grego foi dividido em quatro partes de acordo com as regiões e com os líderes desses lugares: Ptolomeo no Egito, Palestina e parte de Síria; Casandro que dominou a Macedônia se nomeou líder da Grécia; Lisímaco anexou a região da Tracia e uma grande parte do Ásia Menor; e Seleuco que possuiu parte do Ásia Menor, o norte de Síria, Mesopotâmia e o oriente (anteriormente territórios dos persas).

Na região de Jerusalém, o domínio grego foi sucedido por Antígono, e posteriormente por Ptolomeu, e iniciou-se um período de lutas constantes na região entre Ptolomeu IV e Antíoco III, que foi dominador grego na região da Síria. Durante os últimos 200 anos a.C., Jerusalém foi alvo de disputas entre a dinastia dos Ptolomeus (IV e V) contra Antíoco (III e IV). Em 198, Antíoco conquistou a Palestina.

Antíoco IV se empenhou para difundir a cultura grega na cidade e, para isso, ele criou um local de exercícios físicos em Jerusalém, invadiu o santuário e levou os utensílios do templo e dedicou um altar a Zeus no altar de bronze do templo judeu. 
Soma-se a isso o fato de que, em 167 a.C., foi construída uma cidadela próxima ao templo com o intuito de fortalecer o controle dessa área. De acordo com 1 Macabeus 1.33-36, os judeus viram-se obrigados a ficar nas mãos dos dominadores grego-sírios e viviam lutando contra a influência grega na região:

Então reconstruíram a Cidade de Davi, dotando-a de grande e sólida muralha e de torres fortificadas, e dela fizeram a sua Cidadela [...] Abasteceram-na de armas e víveres e nela depositaram os despojos tomados em Jerusalém, tornando-se assim uma armadilha enorme para nós. Aquilo era uma emboscada para o lugar santo, um adversário maléfico para Israel constantemente. (BÍBLIA DE JERUSALÉM, 2006).

Diante disso, fica pressuposto que os judeus dessa região demonstraram resistência a influência grega, e isso gerou uma reação por parte de alguns religiosos como Judas Macabeu e seus irmãos, Jônatas e Simão. Durante os anos 167 - 64 a.C., foi um período de luta dos judeus para reestabelecer sua religião com seu culto no templo em Jerusalém. Mas vale lembrar que a resistência ao helenismo por parte dos judeus gerou perseguição ao povo de Deus. Conforme o texto de 1 Macabeus descrito acima, os judeus passaram por terrores e tormentas durante esse período:

O grande elemento fomentador da literatura apocalíptica foi a perseguição. O povo oprimido luta com as suas armas para, pelo menos, continuar vivo. Em situações semelhantes, é muito comum a associação da fé com a imaginação: a fé apresenta as formas imprecisas em seus detalhes, e a imaginação fornece o conteúdo, completando o que fora apenas pontilhado pela fé. Assim, o povo de Israel, em meio aos seus sofrimentos lançava as suas expectativas em forma de literatura, querendo crer na vinda triunfante do Messias com a sua espada flamejante, para exterminar os seus opressores. Visto que a história para os judeus era um catálogo de desastres, a partir do qual se lhes tornou evidente que nenhum libertador humano poderia resgatá-los. (COSTA, 1992, p. 33-34).

Os sentimentos de pavor e frustração por parte dos judeus serviram de fonte de imaginação criadora para a literatura desse período produzida pelos autores: "Referimo-nos às perseguições movidas pelos sírios contra os judeus, após a morte de Alexandre, o Grande. Quando esta perseguição recrudesceu, multiplicou-se a literatura apócrifa.” (TOGNINI, 1987, p. 23). 
Trata-se, então, de um pathos religioso. Etimologicamente pathos significa sofrimento/paixão, e ele é um dos componentes da retórica clássica, juntamente com o ethos e o logos. Aqui pathos diz respeito às circunstâncias que geram a produção do discurso por parte do comunicador. Por isso, pode-se dizer que a perseguição que os autores judeus sofreram serviu de pathos religioso à criação literária no período interbíblico.

Feitas essas considerações a respeito da dominação grega em Jerusalém, nosso objeto é verificar a influência grega na região do Egito, mais especificamente em Alexandria. Em 332 a.C., Alexandre fundou a cidade de Alexandria (nome que o homenageia) com o objetivo de tê-la como uma base militar estratégica para seu planejamento e suas ações. Tal escolha deu-se pela localização estratégica de Alexandria: no delta do Nilo (Egito), o que garantia a ligação entre os continentes pelo acesso ao Mediterrâneo.

Alexandria tornou-se uma cidade cosmopolita por vários motivos: nela estavam reunidos gregos, judeus e egípcios; serviu de centro comercial pelo fato de ser a rota oficial do comércio via Mediterrâneo; além de ter sido um centro de comunicação que acabou por atrair pessoas instruídas, cultas, com desejo de expansão intelectual e comercial.

A cidade acabou por tornar-se um centro de difusão do helenismo: “o helenismo nasceu em Alexandria” (ENCICLOPÉDIA DA BÍBLIA, 20o8, p. 186). O surgimento do Museu Alexandrino em 280 a.C. fundado por Demétrio, que era um seguidor de Aristóteles, garantiu a formação desse polo difusor de conhecimento grego.

Além disso, muitos eruditos que vieram para Alexandria formaram o que veio a ser denominado de "Era de Prata da literatura grega" (ENCICLOPÉDIA DA BÍBLIA, 2008, p. 186), ou seja, uma concentração de estudiosos da língua e literatura grega clássica, o que possibilitou a formação de judeus da região com esse conhecimento. Como resultado disso, entre os terceiro e segundo séculos a.C., 
surgiu uma das maiores produções de Alexandria: a Septuaginta (LXX). Trata-se da versão grega do Antigo Testamento elaborada por judeus que tinham apreço pela literatura e cultura grega.

Todos esses aspectos servem para demonstrar que a biblioteca de Alexandria não pode ser entendida como um local de arquivo ou depósito de livros. Pelo contrário, como "casa das musas" (esse é o significado do termo museu), a biblioteca tornou-se um centro de transmissão do saber, uma vez que nela foram feitas traduções de textos antigos.

Portanto, a Biblioteca de Alexandria proporcionou aos judeus o contato com o mundo grego, tanto que os responsáveis pela LXX manifestaram a assimilação com a língua grega e com questões da arte literária dos gregos: "No solo traducirán la Ley judia al griego sino que ensayarán prácticamente todos los géneros literários practicados por los griegos: la tragédia de tema bíblico y talvez el teatro [...] la épica [...] la filosofia [...]” (FERNÁNDEZ, 2000) Assim, na perspectiva desse autor, os judeus sábios de Alexandria valeram-se dos gêneros literários dos gregos para recontar a história do povo hebreu, antes mesmo de seus historiadores antigos como Flavio Josefo e Fílon.

A difusão do helenismo na Palestina e no Egito incidiu sobre os judeus que habitavam nessas regiões. Com o passar do tempo, muitos judeus doutos passaram a ordenar seu pensamento e suas ideias valendo-se de formas que tivessem o prestígio da uma tradição reconhecida. Por isso, neste estudo, entendemos que a formação do gênero é decorrente de um processo de aprendizagem formal. Ainda que no AT e NT ocorra a recolha de textos divinamente inspirados, os autores humanos recorreram a recursos correntes para expressarem a mensagem divina.

Especificamente no Período Interbíblico não houve inspiração divina, contudo houve a assimilação e transformação de formas textuais que foram se categorizando com o passar do tempo. 
Como o gênero possui uma estrutura que também lhe caracteriza (há outros fatores que o definem), os judeus puderam incorporar estruturas linguísticas, fórmulas, estilos, etc., de obras que foram referência de expressão artística na literatura grega do Período Interbíblico. Trata-se, então, de um processo histórico. Avaliando-se esse processo, pode-se inferir que as reflexões a respeito dos gêneros literários podem também contribuir para uma historiografia dos textos sagrados antigos.

Por fim, entendemos que estudar as questões da produção literária do Período Interbíblico nos permite avaliar se os aspectos formais da literatura judaica deste período serviram de base (ou não) para os autores no NT, mais especificamente na questão do gênero apocalíptico.

\section{Definição e características do gênero apocalíptico}

Nosso objetivo é apresentar o leque de definições feitas pelos estudiosos ao longo dos anos com o intuito de apresentar desde a etimologia da palavra apocalipse até as definições atreladas a diversos aspectos como contexto histórico e características internas. Assim, iniciamos nossa discussão a respeito da definição do gênero apocalíptico por meio dos seus elementos constituintes. Partimos da ideia de que esse gênero possui pelo menos dois aspectos fundamentais: é tanto um tipo de literatura quanto um conjunto de conceitos específicos encontrados em textos pertencentes a esse gênero.

A discussão a respeito dos conceitos específicos encontrados no gênero em questão pode ser apresentada da seguinte maneira: o texto apocalíptico implica a comunicação reveladora de mistérios ocultos por um mensageiro a um profeta que, por sua vez, apresenta a mensagem recebida por meio de visões em uma estrutura literária, mais especificamente em forma de narrativa. Para Osborne (2009), as visões da mensagem recebida pelo profeta: 
conduzem os leitores a uma realidade transcendente, que é superior à situação presente e encoraja os leitores a perseverarem em meio às provações. As visões contrariam a experiência normal, ao revelar os mistérios divinos no mundo real e descrever a crise atual como uma situação temporária, ilusória. Isso se torna possível pela transformação operada por Deus neste mundo em favor cristão. (OSBORNE, 2009, p. $352)$.

Com relação a etimologia, o termo apocalipse remete a ideia de desvendar, tirar o véu, ou seja, revelar, colocar o que está oculto à luz do dia. Sua origem vem

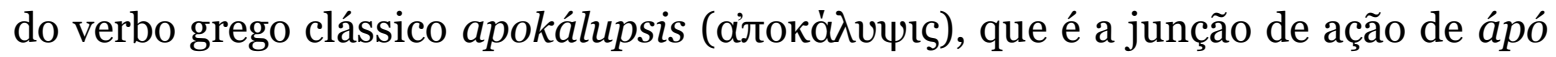

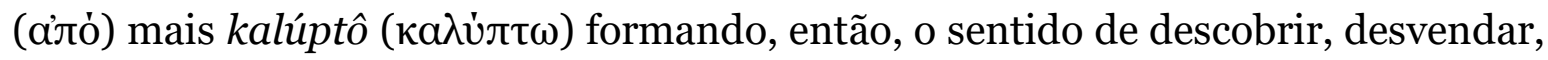
tirar o véu, ou seja, revelar.

Esse conceito teve seu início na mitologia grega, mais especificamente na Odisseia, de Homero, quando o herói Ulisses naufragou numa ilha em que Calipso habitava. Calipso era uma ninfa que vivia escondida em uma gruta, e sua ação foi acolher Ulisses em sua morada e, uma vez apaixonada pelo herói, escondeu-o por

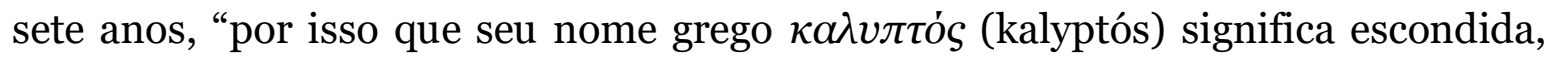
oculta, coberta." (TORRES, 2015, p. 16)

Já D. S. Russel não define o gênero apocalíptico estritamente pela etimologia, antes o faz pelo seu aspecto histórico. Para ele, o gênero apocalíptico "era, essencialmente, um fenômeno literário que emergiu no Judaísmo durante o domínio do rei selêucida Antíoco Epífanes (175-163 a.C.)” (RUSSELL, 1978, p. 3 apud SOARES, 2008, p. 100). E continua:

\begin{abstract}
A palavra "apocalíptico" é derivada do substantivo grego apokalypsis, que significa "revelação". Entretanto, seu uso, com referência a esse gênero de literatura, é devido com toda probabilidade não ao caráter revelatório dos livros em questão, mas preferivelmente ao fato de que eles têm muito em comum com o Apocalipse do Novo Testamento, com seu linguajar esotérico, sua imaginação bizarra e seus pronunciamentos relativos à consumação de todas as coisas em cumprimento das promessas de Deus. (RUSSELL, 1978, p. 3 apud SOARES, 2008, p. 100).
\end{abstract}

E Soares (2008, p. 102) apresenta a definição de gênero proposta por Klaus Koch enfatizando que, para esse estudioso, o termo apocalipse diz respeito a um macrogênero que comporta vários subgêneros. Por isso ele faz a diferenciação entre 
apocalipse, que é o gênero propriamente dito, e apocalíptica que remete ao movimento intelectual que se configurou no período interbíblico, época marcada pela ausência da voz divina e predomínio da imaginação criadora (como já vistos no capítulo anterior).

Vale ressaltar que, para Costa (1992), o verbo revelar e o substantivo apocalipse não eram utilizados com o sentido religioso no mundo helênico. E acrescenta:

somente a partir do $1^{\circ}$. século a.C. é que a palavra passou a ser empregada num sentido profundamente religioso. Como os judeus não dispunham, em seu idioma, de um termo correspondente, quando se referiam à literatura apocalíptica, usavam a palavra "profecia". (COSTA, 1992, p. 25).

John J. Collins propôs uma definição de apocalipse por meio da estrutura do texto, levando em consideração os aspectos de forma e conteúdo e, assim, desenvolveu uma abordagem funcional para o gênero apocalíptico. Para ele:

Apocalipse é um gênero de literatura revelatória com estrutura narrativa. A revelação ao destinatário humano é mediada por um ser de outro mundo, que descortina uma realidade ao mesmo tempo temporal, uma vez que retrata uma salvação escatológica, visto que envolve outro mundo, que é sobrenatural. (COLLINS, 1979, p. 9 apud KOSTENBERGER; PATTERSON, 2015, p. 481).

Então, a partir desses aspectos funcionais do gênero, passamos para as considerações do gênero levando em consideração forma, conteúdo e também a função exercida no momento de sua produção. Com base nisso, podemos articular o texto com seu contexto de produção e as suas características internas. E, por meio de texto-contexto/forma/conteúdo/função, temos, então, subsídios para definição e características do gênero apocalíptico. Assim, entendemos que o gênero deve ser definido tanto por suas características literárias quanto por seus aspectos de conteúdo. 


\subsection{As características do gênero apocalíptico}

Os estudos contemporâneos dos gêneros literários não têm se voltado para a discussão a respeito da distinção entre um tipo ou outro tipo de texto. Muito pelo contrário, desde a modernidade a teoria literária tem discutido a existência de um denominador comum entre um determinado gênero com seus objetivos artísticos e suas características compartilhadas com outras formas de expressão.

Entretanto, neste estudo, nosso objetivo é o de contemplar tanto as considerações literárias de um gênero como os elementos constituintes do gênero que o caracterizam. Para isso, partimos de uma proposta básica das características do gênero apocalíptico para, então, procedermos a uma classificação que integre forma, conteúdo e função.

há certos traços gerais que são característicos da literatura como um todo e que justificam a classificação de 'apocalíptica' como um tipo literário: a presença de um dualismo cósmico, visões e revelações; um contraste entre a presente era maligna e a vindoura era escatológica; pessimismo concernente à presente era e otimismo concernente à era por vir; referências e alusões a mitologia, a numerologia e a simbolismo animal; a ideia da unidade da história e de um objetivo em direção ao qual a história se move; o desenvolvimento da crença na vida após a morte, e especialmente na ressurreição dos justos e no julgamento dos ímpios (não há ressurreição para os injustos mortos); e o aparecimento de uma figura transcendente identificada como "o Filho do homem" [...] Russell sugere quatro características literárias distintas da literatura apocalíptica. Ela é esotérica no caráter, literária na forma, simbólica na linguagem e pseudônima na autoria. (ENCICLOPÉDIA DA BÍBLIA, 2008, p. 992).

Podemos então, discorrer a respeito dessa definição categorizando o gênero em características gerais, aspectos formais, conteúdo e função. Esses elementos encontram-se nos livros produzidos no período interbíblico, e alguns deles também no Apocalipse canônico de João (a pseudonímia, por exemplo, não é uma característica encontrada no Apocalipse, de João).

Kostenberger e Patterson (2015, p. 482) apresentam estas características gerais do gênero apocalíptico: um meio de comunicação visionário ou revelatório; linguagem simbólica, figurada e metafórica; dualismo entre as realidades terrena e 
celestial. E é importante considerar que essas características gerais evocam aspectos de forma e conteúdo do gênero.

A comunicação por meio de uma visão/revelação é um elemento fundamental nesse tipo de literatura. Pelo fato de estarem sem a voz divina, os autores do período interbíblico valeram-se de visões extáticas como um meio para falar dos planos divinos para seu povo.

A linguagem figurada é a expressão da imaginação criadora decorrente da ausência da voz divina. Isso não quer dizer que ela não seja encontrada nos livros canônicos, mas aqui se trata de um uso que os autores fizeram para dizer o que não pode ser dito, tendo em vista a ausência de uma situação similar. Assim, o recurso comunicativo foi o símbolo, a metáfora, etc.

O dualismo entre vida terrena e vida celestial é decorrente da visão/revelação recebida. E isso está atrelado ao contexto histórico: uma vez que do lado de cá o povo estava em perseguição, assim sendo, a visão do mundo vindouro só poderia apresentar um caráter oposto ao da realidade presente.

Feitas essas considerações, podemos, então, identificar os aspectos formais do gênero. O primeiro aspecto a ser destacado é o uso de mediadores da visão/revelação do mundo vindouro. Nesse aspecto, entendemos que, para se revelar realidade celestial, era necessário um agente que servia de intermediário para a comunicação. Em algumas obras, essa mediação poderia ser feita por meio de um anjo.

O segundo aspecto diz respeito à pseudonímia. Com a ausência da voz divina, os autores humanos recorreram às personagens bíblicas para dar voz às suas angústias e questões, e isso também servia de homenagem e reconhecimento aos vultos da história dos judeus: 
Acredita-se que todos os apocalipses judaicos existentes sejam pseudonímicos, ou seja, escritos como se fossem da autoria de antigas figuras de destaque como Adão, Enoque, Moisés, Daniel, Esdras e Baruque. Apenas os apocalipses cristãos mais antigos, o Apocalipse, de João e $O$ Pastor, de Hermas, foram escritos sob o nome de seus verdadeiros autores. (DICIONÁRIO TEOLÓGICO DO NOVO TESTAMENTO, 2012, p. 101).

Especificamente nos apocalipses judaicos vê-se que o uso do nome das personagens conhecidas do AT se deu como uma estratégia de aceitação desses textos por parte dos judeus, tendo em vista que o testemunho dos que chamavam para a si a responsabilidade de profeta não era favorável e "ao assim se projetarem no passado, os autores de apocalipses podem colocar em forma de profecia sumários da atuação divina com seu povo e com o mundo." (CARSON; MOO; MORRIS, 2008, p. 533) Soma-se a isso o fato de que, ao usar o nome de uma personagem bíblica, os autores não seriam descobertos por seus inimigos e poderiam beneficiar todo o povo com sua mensagem.

O último aspecto diz respeito à visão autobiográfica expressa em narrativa. Quando o autor se expressava na composição de seu texto, ele o fazia por meio dos elementos estruturais da narrativa: personagens, tempo, espaço, enredo e ação, foco narrativo, etc.

Com relação ao conteúdo do gênero, entendemos que há temas recorrentes na literatura apocalíptica, como proposto por Osborne (2009, p. 358-360): pessimismo na era presente, promessa de salvação, uma visão da realidade transcendente centrada na presença e no controle de Deus, determinismo divino em que Deus controla toda a história, dualismo entre era presente e a era do porvir, e recriação do cosmos.

Como todo esse tipo de texto está vinculado a um momento histórico, percebemos que os elementos de conteúdo remetem à crise que o povo vinha sofrendo durante o período de perseguição nos últimos séculos do período interbíblico. O conteúdo dos livros apresentam a ação e intervenção divina em favor de seu povo, preservando-os ainda que eles se vissem em meio a ataques culturais, políticos e religiosos do helenismo. Nesse embate, fica claro que a 
realidade temporal e espacial colocam em destaque as realidades celestiais em detrimento das circunstâncias terrenas para que, então, o povo de Deus tenha conforto em meio ao sofrimento.

Por fim, destacamos a função que o gênero desempenhou no período interbíblico. O gênero incorporou características, forma e conteúdo para cumprir o objetivo de fortalecer a fé dos judeus no Deus da lei e, assim, fazê-los fiéis ainda que em meio ao sofrimento e à crise. Por meio de seu conteúdo, o gênero reuniu as diretrizes da lei para o viver e a chamada divina para suportar o sofrimento em meio a dor.

Portanto, podemos afirmar que só é possível falar de gênero apocalíptico quando se leva em consideração características da literatura, sua forma e conteúdo, e sua função. Destacamos que teólogos que estudam o NT se utilizam dessas categorias como roteiro para análise do Apocalipse de João, mas também afirmam que esse livro é considerado sui generis, pois apresenta algumas dessas marcas com uma configuração interna particular.

\section{Conclusão}

Feitas as considerações teóricas e analíticas nesta pesquisa, podemos tecer algumas considerações finais como resultado de nossa investigação. Percebemos os estudos dos gêneros literários à luz da Teoria Literária podemos serve de ferramenta para a análise dos gêneros literários existentes na Bíblia. O estudo dos gêneros nos conduz a uma investigação intra-corpus no texto bíblico com o intuito de detectar de que maneira a linguagem carregada de sentido, a cosmovisão do autor e o lócus enunciativo do autor se amalgamaram no processo criativo do texto.

Nesse sentido cumpre-nos reforçar que os gêneros possuem uma natureza literária, isto é, ele é uma criação artística e isso o difere da linguagem cotidiana que serve para o compartilhamento de informações, para a ação coletiva, etc. O texto literário é uma criação artística no qual estão presentes as representações que o poeta fez; "o texto da literatura é um objeto de linguagem ao qual se associa uma 
representacão de realidades físicas, sociais e emocionais mediatizadas pelas palavras da língua na configuração de um objeto estético.” (PROENÇA, 2007, p. 8).

Essas considerações também nos permitem reforçar que a literatura é um instrumento de conhecimento. Não foi sem propósito que os filósofos antigos se propuseram a discutir a arte literária, pois viram nela representações da realidade. Com o passar dos tempos essa ideia tem se confirmado na medida em que a literatura tem condições de "exprimir o homem" (CANDIDO, 1999), e este tem feito uso da arte para buscar a compreensão da realidade.

No estudo do período interbíblico pudemos perceber que "a matéria literária é cultural." (PROENÇA, 2007, p. 37) O autor do texto literário se valeu de elementos do seu contexto cultural para compor sua representação. Assim, Proença (2007, p. 37) afirma que se se pode falar em literatura judaica, isso passa a ser um indicativo de que há um povo e uma cultura expressos no texto literário.

As categorias características gerais, forma, conteúdo e função serviram de guia investigativo do gênero apocalíptico e flexibilizam a análise de cada livro a ser estudado seja ele inspirado ou não.

Uma outra consideração a ser feita é que este estudo serve de auxílio ao pregador e também ao professor na medida em que relaciona a pesquisa contextual do texto bíblico com a linguagem literária. Dessa forma, esta pesquisa pode auxiliar a professores de Hermenêutica e Exegese Bíblicas a articular os aspectos estéticos do texto com os elementos que compõem o contexto.

Sugerimos, ainda, a continuidade desta pesquisa ampliando-a os demais gêneros literários encontrados na Bíblia. Nessa investigação dos demais gêneros poder-se-ia discorrer a respeito dos elementos estruturais de cada forma literária bíblica por meio da linguagem literária inerente ao texto bíblico. 


\section{REFERÊNCIAS}

ARISTÓTELES. Arte poética. São Paulo: Martin Claret, 2011.

A BÍBLIA DE JERUSALÉM. São Paulo: Paulus, 2006.

BITTAR, Eduardo C. B. Curso de filosofia aristotélica. Leitura e interpretação do pensamento aristotélico. Barueri: Manole, 2003.

CANDIDO, Antonio. A Literatura e a formação do homem. Revista do Departamento de Teoria Literária, Campinas, p. 81-90, 1999.

CARSON, Donald. A.; MOO, Douglas J.; MORRIS, Leon. Introdução ao Novo

Testamento. São Paulo: Vida Nova, 2008.

COELHO, Nelly N. Literatura \& linguagem. 2. ed. São Paulo: Quíron, 1976.

COLLINS, J. J. (Ed.). From prophecy to apocalypticism: The expectation of the end. In: The encyclopedia of the apocalypticism. The origins of apocalypticism in Judaism and Christianity. New York: Continum, 2000, p. 129-161.

COLLINS, J. J. Introduction: towards the morphology of a genre. Semeia, Atlanta, v. 14, p. 1-19, 1979, Disponível em:

<http://search.ebscohost.com/login.aspx?direct=true\&db=rfh\&AN=ATLAooo0771226\&si te=ehost-live $>$. Acesso em: 04 nov. 2017.

COLLINS, J. J. The apocalyptic imagination: An introduction to jewish apocalyptic literature. 2. ed. Grand Rapids: William B. Eerdmans Publishing Company, 1998.

COSTA, Hermisten Maia Pereira. A literatura apocalíptico-judaica. São Paulo: Casa Editora Presbiteriana, 1992.

DANA, H. E. O mundo do Novo Testamento. Rio de Janeiro: Juerp, 1980.

ENCICLOPÉDIA DA BÍBLIA. São Paulo: Cultura Cristã, 2008. v. 5.

DICIONÁRIO TEOLÓGICO DO NOVO TESTAMENTO: compêndio dos mais avançados estudos da atualidade. São Paulo: Vida Nova; Loyola, 2012.

FEE, Gordon D.; STUART, Douglas. Entendes o que lês? Um guia para entender a Bíblia com o auxílio da exegese de da hermenêutica. São Paulo: Vida Nova, 2011.

FERNÁNDEZ, Marcos N. Oriente y occidente en la biblia de Alejandría. Estudios eclesiásticos, v. 75, n. 292, p. 3-21, jan. 2000.

FRAME, John M. A doutrina da palavra de Deus. São Paulo: Cultura Cristã, 2013. 
HANSON, Paul D. The dawn of apocalyptic: the historical and sociological roots of jewish apocalyptic eschatology. Philadelphia: Fortress, 1979c.

$\mathrm{KOCH}$, Klaus. The rediscovery of apocalyptic: a polemical work on a neglected area of biblical studies and its damaging effects on theology and philosophy. Bloomsbury: Scm press, 1970.

KOSTENBERGER, Andreas J.; PATTERSON, Richard D. Convite à interpretação bíblica. A tríade hermenêutica (história, literatura e teologia). São Paulo: Vida Nova, 2015 .

LOPES, Augustus Nicodemus. A Bíblia e seus intérpretes. Uma breve história da interpretação. 3. ed. São Paulo: Cultura Cristã, 2013.

MARCUSCHI, Luiz A. Produção textual, análise de gêneros e compreensão. São Paulo: Parábola, 2008.

OSBORNE, Grant R. A espiral hermenêutica. São Paulo: Vida Nova, 2009.

PROENÇA, Domício. A linguagem literária. São Paulo: Ática, 2007.

PROVAN, Lain W.; LONG, V. Philips; LONGMAN, Tremper. Uma história bíblica de Israel. São Paulo: Vida Nova, 2016.

RAD, Gerhard V. Old testament theology: the theology of Israel's prophetic traditions. New York: Harper \& Row, 1965.

ROWLEY, H. H. A importância da literatura apocalíptica: um estudo da literatura apocalíptica judaica e cristã de Daniel ao apocalipse. São Paulo: Paulinas, 1980.

RYKEN, Leland. Formas literárias da Bíblia. São Paulo: Cultura Cristã, 2017.

SOARES, Dionísio Oliveira. A literatura apocalíptica: o gênero como expressão. Horizonte, Belo Horizonte, v. 7, n. 13, p. 99-113, 2008.

TOGNINI, Enéas. O período interbíblico. 6. ed. São Paulo: Louvores do Coração, 1987.

TORRES, Antonio César. A linguagem (Re) velada do livro do apocalipse. Pouso Alegre, 2015. Dissertação (Mestrado em Ciências da Linguagem) - Programa de PósGraduação em Ciências da Linguagem, Universidade do Vale do Sapucaí.

WELLEK, René; WARREN, Austin. Teoria da literatura e metodologia dos estudos literários. São Paulo: Martins Fontes, 2003.

ZILBERMAN, Regina. Literatura infantil na escola. 11. ed. São Paulo: Global, 2003. 